\title{
Demographic response to environmental variation in breeding, stopover and non-breeding areas in a migratory passerine
}

\author{
Michael Schaub · Hans Jakober • Wolfgang Stauber
}

Received: 26 July 2010/ Accepted: 5 April 2011/Published online: 22 April 2011

(C) Springer-Verlag 2011

\begin{abstract}
Demographic rates of migratory species passing through several areas during their annual cycle may be affected by environmental conditions at each of these areas. Recent studies provide evidence that their impact is not necessarily immediate, but can be delayed. We studied survival, reproductive success and arrival date at the breeding grounds of red-backed shrikes Lanius collurio, a trans-Saharan migrant, in relation to weather and vegetation on the breeding grounds, the stopover sites during migration and in the wintering areas. These environmental factors are used as proxy of the shrike's food supply. We analysed detailed demographic data of some 4,600 individuals from 25 years with multistate capture-recapture and mixed models. Survival probabilities of juveniles and breeders of both sexes varied in parallel across time, suggesting that all cohorts were sensitive to similar causes of mortality. Reproductive performance increased with
\end{abstract}

Communicated by Douglas Robinson.

Electronic supplementary material The online version of this article (doi:10.1007/s00442-011-1999-8) contains supplementary material, which is available to authorized users.

M. Schaub ( $\square)$

Swiss Ornithological Institute, 6204 Sempach, Switzerland

e-mail: michael.schaub@vogelwarte.ch

M. Schaub

Division of Conservation Biology,

Institute of Ecology and Evolution, University of Bern,

Baltzerstrasse 6, 3012 Bern, Switzerland

H. Jakober

Friedrichstrasse 8/1, 73329 Kuchen, Germany

W. Stauber

Bismarckstrasse 6, 73333 Gingen/Fils, Germany temperature and decreased with rainfall on the breeding area. Moreover, it increased with vegetation cover in the Sahelian stopover area used on autumn migration suggesting a carry-over effect. Arrival date was negatively affected by spring temperatures in the breeding area. Hence, demographic rates were affected by environmental factors on the breeding grounds, but also outside and elsewhere. This suggests that the shrike's population dynamics are driven by environmental factors operating at various scales of space and time. However, only a small amount of the temporal variation in demographic rates is explained by the environmental factors considered, suggesting that additional factors, such as those operating during migration, might be important.

Keywords Carry-over effect · Demography · Migration · NDVI · Lanius collurio

\section{Introduction}

Migratory birds are influenced by varying environmental factors of many different sites on the breeding and wintering grounds and along their migratory route. These may have immediate or delayed impacts on demographic rates. Examples of an immediate impact are reduced reproductive output and low survival due to a poor food availability during breeding (Thomson et al. 1996; Veistola et al. 1997; Cowley and Siriwardena 2005; Geiser et al. 2008) or an increased mortality because of a low food availability outside the breeding season (Peach et al. 1990; Kanyamibwa et al. 1990; Baker et al. 2004; Schaub et al. 2005). Examples of delayed impact on demographic rates are reduced reproductive output and later arrival on the breeding grounds as a result of a scanty food supply in the 
non-breeding area or at stopover sites (Marra et al. 1998; Norris et al. 2004; Saino et al. 2004a, b; Gordo and Sanz 2008; Harrison et al. 2011). Such carry-over effects are likely to be induced by physiological constraints (Harrison et al. 2011). If food is short, birds may have poor energy stores (Marra et al. 1998), possibly reducing the speed of moult, of pre-migratory fattening (Bearhop et al. 2004) or of male gonad growth (Bauchinger et al. 2008).

Besides environmental factors, density dependence operating through depletion of and competition for resources is also an important reason for variation in demographic rates (Moore and Yong 1991; Rodenhouse et al. 2003). Since the carrying capacity is likely to differ between sites visited, the strength of density dependence is likely to differ as well. Consequently, population regulation can be a function of density at any subset or all of wintering, stopover or breeding areas (Runge and Marra 2005; Newton 2008).

Density and environmental effects on demographic rates can operate singly or in combination, their impact may change from one area to another and the response may be immediate or delayed. Due to this complexity, understanding population dynamics of migrants is a real challenge (Runge and Marra 2005; Ratikainen et al. 2008). Nevertheless, for the conservation of migratory species, it is crucial to assess the relative importance of factors working at different staging areas on population dynamics (Webster et al. 2002).

In this paper, we study annual survival, components of reproductive success and arrival date of a trans-Sahara migrant, the red-backed shrike Lanius collurio. We test for impacts of environmental variation at breeding and wintering grounds, as well as along the migratory route. The dynamics of several red-backed shrike populations are driven by density-dependent and density-independent factors (Pasinelli et al. 2011). The demographic mechanisms for population changes are unknown, but it is to be expected that some demographic rates, which are components of population growth, vary as a result of changes of the environment or in density. Red-backed shrikes breed in Europe from May to August and migrate to the eastern Sahel for staging from September to October (Pearson and Backhurst 1976; Pearson 1990; Berthold et al. 2001). This area dries out and becomes less and less suitable for the shrikes. In response, the birds move on to south-eastern Africa where they stay from November until the end of March and moult (Harrison et al. 1997). The migration back to the breeding areas is rapid and without prolonged stopovers, following a more easterly route than in autumn (Lefranc 1993; Glutz von Blotzheim and Bauer 1993; Harris 2000). To study the demography of red-backed shrikes, we analysed data of 25 years from southern Germany and related them to weather and vegetation parameters at all stationary stages in the bird's life and to the size of the breeding population. Our particular aims were (1) to assess how strongly arrival date is affected by environmental factors at the African stopover and wintering areas, (2) to evaluate how strongly reproduction and survival are affected by environmental factors encountered before, during and after breeding, and (3) to assess how strongly reproduction and survival are affected by breeding population density and environmental factors at sites the shrikes use throughout the annual cycle.

\section{Materials and methods}

\section{Study species}

The red-backed shrike is a medium-sized (body mass c. $30 \mathrm{~g}$ ), migratory passerine breeding in agricultural landscapes (Glutz von Blotzheim and Bauer 1993). It feeds mostly on large invertebrates like beetles or grasshoppers. Red-backed shrikes breed in open nests in hedgerows or bushes and typically raise one brood of 3-7 nestlings. The main non-breeding habitats are arid savannahs (Bruderer and Bruderer 1993, 1994; Jakober et al. 2007). Although winter site fidelity has been reported (Herremans and Herremans-Tonnoeyr 1995), shrikes seem quite opportunistic, with local concentrations building up shortly after large amounts of food become available (Bruderer and Bruderer 1994). The main food during the non-breeding season are invertebrates (mainly grasshoppers; Bruderer and Bruderer 2008). Spring migration progresses rapidly and without prolonged stopovers (Lefranc 1993; Glutz von Blotzheim and Bauer 1993; Harris 2000).

Reproductive success of red-backed shrikes depends on temperature and rainfall, being higher during warm and dry conditions (Jakober and Stauber 2004; Husek and Adamik 2008), and on nest predators (Roos and Pärt 2004; Müller et al. 2005). It is unknown, however, whether reproduction is subject to a carry-over effect, also depending on the conditions experienced in wintering or stopover areas. Variation in survival probabilities is poorly known in red-backed shrikes and it is unclear whether they are influenced by environmental factors in the wintering or stopover areas. Arrival on the breeding areas appears to have advanced in the course of the last century, but this was neither related to temperatures in spring (Tryjanowski et al. 2002) nor to a large-scale weather index (North Atlantic Oscillation; Hubalek 2003). A comparative study on several red-backed shrike populations showed that their growth rate depended on environmental factors such as the amount of rainfall in the Sahel and in southern Africa as well as on local breeding density (Pasinelli et al. 2011). 
Study site and data sampling

The study was conducted in south-western Germany near Göppingen $\left(48^{\circ} 39^{\prime} \mathrm{N}, 9^{\circ} 47^{\prime} \mathrm{E}\right)$ in a farmland area of $18 \mathrm{~km}^{2}$ consisting mostly of meadows and pastures with interspersed orchards and hedgerows (for a more detailed description, see Jakober and Stauber 1987). In spring, we visited the study area almost daily to record the settlement of shrikes and to resight colour-marked individuals. During numerous visits, we localised the nests of nearly all breeding pairs, recorded reproductive success and ringed the nestlings at an age of about 8 days. Territorial adults were caught with clap or mist nets and ringed with individual colour rings. Between 1981 and 2006, we marked 1,129 adults (616 males, 513 females) of which 340 (214 males, 126 females) were resighted at least once in later years. Some were resighted in several years (up to 7 in males and 4 in females). We also marked 3,598 nestlings; 192 (129 males, 63 females) were resighted at least once in a later year. Some of them were resighted in several years (males up to 6 years, females up to 4 years). From 1982 to 2006, we monitored a total of 1,154 broods of which 760 were successful, and recorded the arrival date of 829 individuals.

\section{Environmental factors and population size}

To describe the environmental conditions, we used data on vegetation cover, temperature and rainfall. Invertebrate availability during breeding is strongly affected by prevailing weather (Schaub 1996), and consequently we used temperature and rainfall as proxy of food availability during breeding. Since, the abundance of phytophagous invertebrates in Africa largely depends on vegetation cover and rainfall (Todd et al. 2002), we regard them as integrative correlates for food availability during non-breeding. Green vegetation cover is indexed reliably by the normalised difference vegetation index (NDVI; Nicholson et al. 1990; Pettorelli et al. 2005). This index, recorded from infrared satellites pictures from the US National Oceanic and Atmosphere Administration (NOAA), measures chlorophyll density of a flat surface. If an area is dry and the vegetation is sparse, NDVI values are low. Based on redbacked shrike occurrence (Fig. 1), we defined three main staging areas in Africa. To describe conditions at the Sahelian autumn stopover area, we calculated the mean NDVI of September and October of each year (Sahelian NDVI). For the main wintering area in southern Africa, we averaged the NDVI for December to March (S-African NDVI). For the spring stopover areas in eastern Africa, we averaged the NDVI values of April (E-African NDVI). We downloaded the NDVI data from http://igskmncnwb015.cr. usgs.gov/adds (accessed 11 November 2009). Rainfall data from Africa were taken from weather stations (13 in autumn, 40 in winter; from http://www.ncdc.noaa.gov/ cgi-bin/res40.pl?page=gsod.html, accessed 11 November 2009) covering the same range (Fig. 1) and time period as for the NDVI data. For each time period, daily precipitation was averaged across all weather stations within the respective area. The mean rainfall per period was expressed as the average of these daily means (hereafter referred to as Sahelian and S-African rainfall). Because the recording of
Fig. 1 Potential African staging areas of red-backed shrikes Lanius collurio. The Sahelian stopover area (grey) is visited in September and October, the main wintering area (vertically hatched) is visited from December to March, and the spring stopover area (horizontally hatched) in April

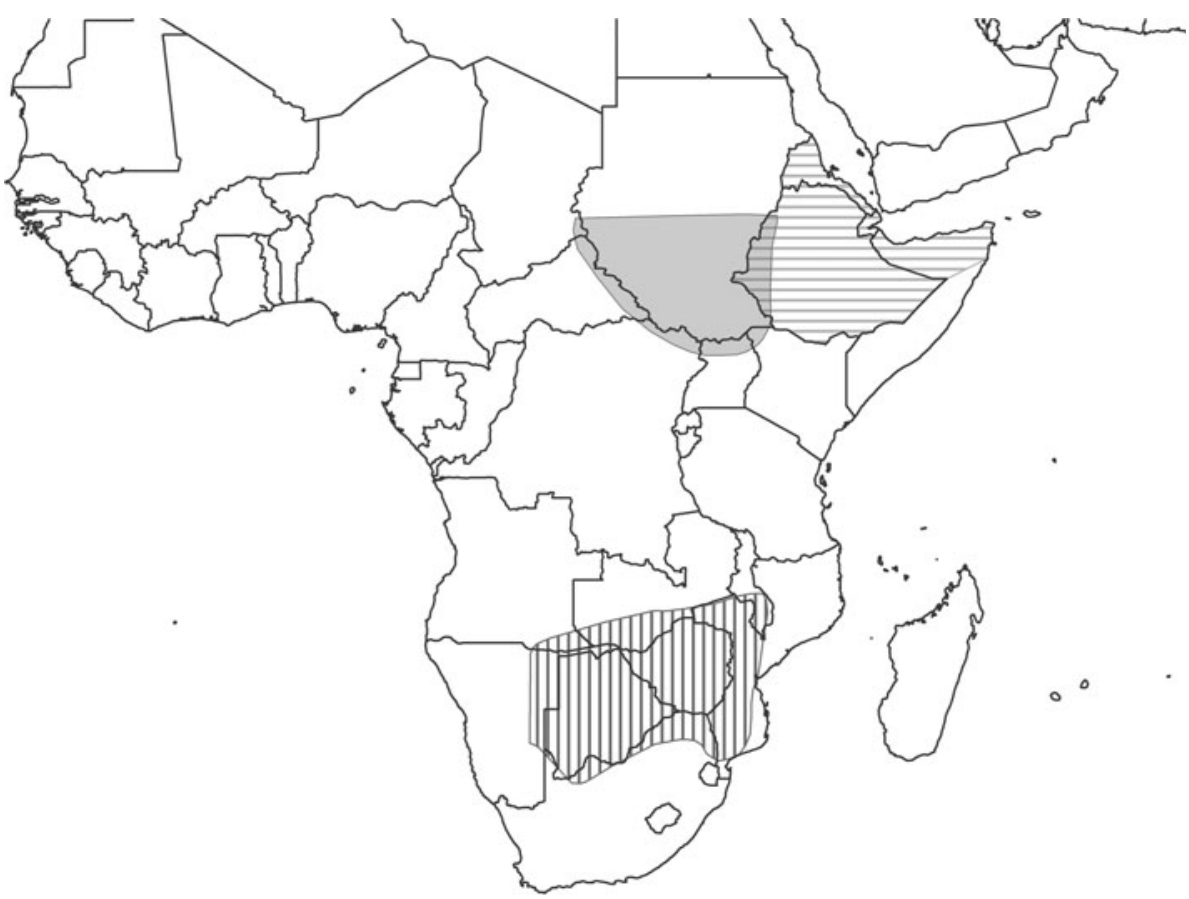


rainfall in the spring staging area in eastern Africa had too many missing values, it could not be considered for the analyses.

To describe the environmental conditions at arrival and during breeding, we used the number of days with rainfall and the mean temperature during May (arrival), and June and July (breeding), respectively. We used temperature data from the weather station Stuttgart-Echterdingen, some $45 \mathrm{~km}$ west of our study area and provided by the Deutscher Wetterdienst (http://metportal.dwd.de/, accessed 15 May 2008), and rainfall data from the station GöppingenJebenhausen some $11 \mathrm{~km}$ west of our study area.

We used the number of established pairs in the study area on 15 June each year as an index of breeding population density. This number is very accurate, because monitoring effort was very high. Using a state-space model to analyse the number of breeding pairs, Pasinelli et al. (2011) found that the observation error was 0 . An accurate measure of population size is important when testing for density dependence, because errors can lead to the detection of spurious density dependence (Freckleton et al. 2006)

The considered explanatory variables covered a wide range of values (Appendix 1 of Supplementary material). Correlations between them were often low $(r=<10.351$, $P>0.08$ ), with a few exceptions (Appendix 2 of Supplementary material).

Estimation of apparent survival and dynamics of reproductive success

Avian reproductive success typically has a strong effect on site fidelity (Haas 1998; Schaub and von Hirschheydt 2009), also evidenced in red-backed shrikes (Jakober and Stauber 1989, 2004; Simek 2001; Pasinelli et al. 2007). Emigration from a study area (i.e. low site fidelity) negatively affects estimates of survival probability as obtained from capturerecapture data. Schaub and von Hirschheydt (2009) recently suggested that additional information on reproductive success should be included in survival analyses within a multistate capture-recapture model, in order to get less biased estimates of survival. This approach requires estimating the probability to reproduce with success, given philopatry and preceding reproductive success. It allows the change of reproductive success from 1 year to the next to be modelled as a function of environmental factors. A main advantage of the multistate capture-recapture model is that state-specific resighting probabilities are explicitly modelled and estimated, ensuring unbiased estimates of apparent survival and transition probabilities (Lebreton et al. 2009). Such an analysis was performed here.

We considered a multistate capture-recapture model consisting of the three states "juvenile" (J), "adult without breeding success" (N) and "adult with breeding success" $(\mathrm{S})$. The model is written with a state transition matrix (states at time $t$ are in rows, states at time $t+1$ are in columns, states from top to down and from left to right ordered as indicated above, $\psi)$ and state-specific vectors of apparent survival $(\phi)$ and recapture $(p)$ :

$\left[\begin{array}{ccc}0 & 1-\psi^{\mathrm{JS}} & \psi^{\mathrm{JS}} \\ 0 & 1-\psi^{\mathrm{NS}} & \psi^{\mathrm{NS}} \\ 0 & 1-\psi^{\mathrm{SS}} & \psi^{\mathrm{SS}}\end{array}\right]_{\mathrm{t}}\left[\begin{array}{c}\phi_{\mathrm{J}} \\ \phi_{\mathrm{N}} \\ \phi_{\mathrm{S}}\end{array}\right]_{\mathrm{t}}\left[\begin{array}{c}0 \\ p_{\mathrm{N}} \\ p_{\mathrm{S}}\end{array}\right]_{\mathrm{t}}$

There are eight different parameter types in this model:

$\psi_{\mathrm{t}}^{\mathrm{JS}}$ probability that an individual born in year $t$ reproduces successfully in year $t+1$, given that it is alive and in the study area in year $t+1$.

$\psi_{\mathrm{t}}^{\mathrm{NS}}$ probability that an adult that did not reproduce successfully in year $t$, reproduces successfully in year $t+1$, given that it is alive and in the study area in year $t+1$.

$\psi_{\mathrm{t}}^{\mathrm{SS}} \quad$ probability that an adult that reproduced successfully in year $t$, reproduces successfully in year $t+1$, given that it is alive and in the study area in year $t+1$.

$\phi_{\mathrm{J}, \mathrm{t}} \quad$ probability that an individual born in year $t$ survives until year $t+1$ and is in the study area in year $t+1$.

$\phi_{\mathrm{N}, \mathrm{t}}$ probability that an adult that did not reproduce successfully in year $t$ survives until year $t+1$ and is in the study area in year $t+1$.

$\phi_{\mathrm{S}, \mathrm{t}} \quad$ probability that an adult that reproduced successfully in year $t$ survives until year $t+1$ and is in the study area in year $t+1$.

$p_{\mathrm{N}, \mathrm{t}}$ probability that an adult that did not reproduce successfully in year $t$ is resighted, given that it is alive and in the study area in year $t$.

$p_{\mathrm{S}, \mathrm{t}} \quad$ probability that an adult that reproduced successfully in year $t$ is resighted, given that it is alive and in the study area in year $t$.

We also used a variant of this model (Eq. 1), in which the probability of adults to reproduce successfully does not depend on the reproductive success in the preceding year (i.e., $\psi^{\mathrm{NS}}=\psi^{\mathrm{SS}}$ ).

We performed a goodness-of-fit test (GOF; Pradel et al. 2003) of a global multistate model in which survival, transition and resighting parameters differed among states, sex and time, using program U-CARE (Choquet et al. 2009a). The GOF was not significant $\left(\chi_{239}^{2}=169.49\right.$, $P=1.00$ ), indicating that the model fits the data adequately.

Model selection

We used program E-SURGE (Choquet et al. 2009b) for modelling and parameter estimation. We formulated 
a priori a number of different models each representing a different combination of one hypothesis for each of the three basic parameter types [resighting $(p)$, apparent survival $(\phi)$, dynamics of reproductive success $(\psi)$ ]. Model selection was based on the Akaike's Information Criterion (AIC) and Akaike weights ( $w_{\mathrm{i}}$; Burnham and Anderson 2002) and was conducted in two steps. First, we tested different hypotheses referring to variation in resighting probability $(p)$ and apparent survival $(\phi)$ while keeping the most complex structure of transitions $(\psi)$. In a second step, we modelled transition probabilities $(\psi)$ using the smallest set of models for resighting and apparent survival for which the $w_{\mathrm{i}}$ sum to 0.95 (95\% confidence set of models). The different hypotheses regarding year and sex effects were the following:

\section{Resighting probability}

Resighting probabilities may have differed among years and may be different between sexes. Yet, we always assumed that the resighting probabilities of successful breeders to be higher than that of unsuccessful breeders, because successful breeders stay longer in the study area and families with fledglings are conspicuous. We considered six additive and interactive submodels for the observation part of the entire model (see Appendix 3 Supplementary material for a complete list of all models).

\section{Apparent survival}

We assumed that apparent survival is age-dependent, i.e. is always different between the first and later years. Factors that might affect apparent survival were sex in both age classes, reproductive success in adults and time. Survival of the different states may vary independently from each other across time, or they may vary in parallel. Independent temporal variation indicates that survival of the different states is influenced by different factors while parallel temporal variation suggests that survival in the different states is affected by the same factors. We used different combinations of these possibilities to define 15 model structures for the survival part of the model (Appendix 3 of Supplementary material).

\section{Change of reproductive success}

In adults, the probability to change reproductive success may be dependent or independent on the reproductive success in the preceding year (Markovian or random transitions, respectively). Moreover, these parameters might also depend on sex, and they may vary indepen- dently from each other across time or in parallel. We defined 15 possible models for the change of reproductive success (Appendix 3 of Supplementary material).

Finally, based on the best model structure, we calculated the proportion of deviance explained by environmental factors and population size. This requires fitting models where the focal parameter $(\theta)$ is time-dependent $\left(M_{\mathrm{t}}\right)$, where it is constant across time $\left(M_{0}\right)$ and one model $\left(M_{\mathrm{x}}\right)$ where $\theta$ is a logit-linear function of a standardised (with mean $=0$ and $\mathrm{SD}=1)$ explanatory variable $(x)$ as $\operatorname{logit}\left(\theta_{t}\right)=\beta_{0}+\beta_{1} x_{t}$.

Following Grosbois et al. (2008), the proportion of deviance of the temporal variance of $\theta$ that is due to $x$ is then calculated as

$R_{\operatorname{dev}}^{2}=\frac{\operatorname{dev}\left(M_{0}\right)-\operatorname{dev}\left(M_{x}\right)}{\operatorname{dev}\left(M_{0}\right)-\operatorname{dev}\left(M_{t}\right)}$, where $\operatorname{dev}\left(M_{\mathrm{t}}\right)$ is the deviance of model $M_{\mathrm{t}}$.

Since nestlings were not sexed when they were ringed (sexing is not possible from morphological characters), we assumed an even sex ratio of nestlings. If this assumption is true, the sex-specific apparent survival probabilities are unbiased (Nichols et al. 2004).

\section{Estimation of reproductive output}

To model reproductive output, we used normal linear models with year and territory as random factors and the environmental factors and population size as fixed effects. Environmental factors and population size were standardised (with mean $=0$ and $\mathrm{SD}=1$ ) to ensure that the estimated slopes could be compared directly. We fitted nine different models; eight had one of the explanatory variables as fixed effect and one had only an intercept. We calculated the proportion of variance of the reproductive success explained by explanatory factors as $R_{v a r}^{2}=1-\sigma_{e n v}^{2} / \sigma_{c o n}^{2}$, where $\sigma_{e n v}^{2}$ is the amount of unexplained temporal variance of reproductive success from a model with an explanatory variable and $\sigma_{c o n}^{2}$ is the amount of unexplained temporal variance of the reproductive success from a model without an explanatory variable (i.e. it is the complete temporal variance).

We performed one analysis with the total reproductive output (i.e. the number of fledglings per breeding pair) and one with the reproductive output of successful breeders only (i.e. the number of fledglings per successful breeding pair). We used both parameters because an explanatory variable might affect (1) the output of successful breeders only, (2) only the probability to reproduce successfully (see above, multistate model) or (3) the combination of the two (total reproductive output). 
Table 1 Model selection for apparent survival $(\phi)$, change in class of reproductive success $(\psi)$ and resighting $(p)$ of red-backed shrikes Lanius collurio (1981-2006)

\begin{tabular}{|c|c|c|c|c|}
\hline Model & Deviance & $K$ & $\Delta \mathrm{AIC}$ & $w_{\mathrm{i}}$ \\
\hline \multicolumn{5}{|c|}{ 1. Step: apparent survival and resighthing (90 models) } \\
\hline$\phi_{[\mathrm{J}, \mathrm{N}, \mathrm{S}] \times \operatorname{sex}+\text { year }}, \psi_{\text {sex } \times \text { year }}^{\mathrm{JS}, \mathrm{NS},}, p_{[\mathrm{N}, \mathrm{S}]+\operatorname{sex}}$ & $5,203.25$ & 183 & $\mathbf{0 . 0 0}$ & 0.646 \\
\hline$\phi_{[\mathrm{J}, \mathrm{N}, \mathrm{S}]+\text { year }}, \psi_{\mathrm{sex} \times \text { year }}^{\mathrm{JS}, \mathrm{NS}, \mathrm{SS}}, p_{[\mathrm{N}, \mathrm{S}]+\mathrm{sex}}$ & $5,211.29$ & 180 & 2.04 & 0.234 \\
\hline$\phi_{[\mathrm{J}, \mathrm{N}, \mathrm{S}]+\text { year }}, \psi_{\text {sex } \times \text { year }}^{\mathrm{JS}, \mathrm{NS}, \mathrm{SS}}, p_{[\mathrm{N}, \mathrm{S}]+\text { sex }+ \text { year }}$ & $5,165.71$ & 204 & 4.46 & 0.069 \\
\hline$\phi_{[\mathrm{J}, \mathrm{S}, \mathrm{N}]+\text { year }}, \psi_{\mathrm{sex} \times \text { year }}^{\mathrm{JS}, \mathrm{NS}, \mathrm{SS}}, p_{[\mathrm{N}, \mathrm{S}] \times \text { sex }+ \text { year }}$ & $5,165.71$ & 205 & 6.46 & 0.026 \\
\hline$\phi_{[\mathrm{J}, \mathrm{N}, \mathrm{S}] * \mathrm{sex}+\text { year }}, \psi_{\text {sex } \times \text { year }}^{\mathrm{JS}, \mathrm{NS}, \mathrm{SS}}, p_{[\mathrm{N}, \mathrm{S}]+\text { sex }+ \text { year }}$ & $5,163.93$ & 207 & 8.68 & 0.008 \\
\hline \multicolumn{5}{|c|}{ 2. Step: change class of reproductive success ( 45 models) } \\
\hline$\phi_{[\mathrm{J}, \mathrm{N}, \mathrm{S}]+\text { year }}, \psi_{\mathrm{sex}+\mathrm{year}}^{\mathrm{JS}, \mathrm{NS}, \mathrm{SS}}, p_{[\mathrm{N}, \mathrm{S}]+\mathrm{sex}}$ & $5,333.372$ & 60 & 0.000 & 0.462 \\
\hline$\phi_{[\mathrm{J}, \mathrm{N}, \mathrm{S}] \times \operatorname{sex}+\text { year }}, \psi_{\text {sex }+ \text { year }}^{\mathrm{JS}, \mathrm{NS}, \mathrm{SS}}, p_{[\mathrm{N}, \mathrm{S}]+\operatorname{sex}}$ & $5,328.187$ & 63 & 0.815 & 0.307 \\
\hline$\phi_{[\mathrm{J}, \mathrm{N}, \mathrm{S}] \times \operatorname{sex}+\text { year }}, \psi_{\text {year }}^{\mathrm{JS}, \mathrm{NS}, \mathrm{SS}}, p_{[\mathrm{N}, \mathrm{S}]+\mathrm{sex}}$ & $5,335.128$ & 60 & 1.756 & 0.192 \\
\hline$\phi_{[\mathrm{J}, \mathrm{N}, \mathrm{S}] \times \text { sex }+ \text { year }}, \psi^{\mathrm{JS}, \mathrm{NS}, \mathrm{SS}}, p_{[\mathrm{N}, \mathrm{S}]+\mathrm{sex}}$ & $5,388.309$ & 36 & 6.937 & 0.014 \\
\hline$\phi_{[\mathrm{J}, \mathrm{N}, \mathrm{S}]+\text { year }}, \psi_{\mathrm{sex}+\text { year }}^{\mathrm{JS}, \mathrm{NS}=\mathrm{SS}}, p_{[\mathrm{N}, \mathrm{S}]+\mathrm{sex}}$ & $5,345.387$ & 58 & 8.015 & 0.008 \\
\hline
\end{tabular}

Modelling was in two steps, and either the $95 \%$ confidence set models (bold) or at least the 5 best models of each step are shown. Complete modelling results are provided in Appendix 4 of Supplementary material. Given are the model deviance, the number of estimated parameters $(K)$, the difference of the AIC between the current and the best model $(\triangle \mathrm{AIC})$ and the Akaike weight $\left(w_{\mathrm{i}}\right)$. Model notations: $J$ state "juvenile", $N$ state "unsuccessful breeder", $S$ state "successful breeder", $J S$ state transition "juvenile" to "successful breeder", $N S$ state transition "unsuccessful breeder" to "successful breeder", SS state transition "successful breeder" to "successful breeder". See Appendix 3 of Supplementary material for model significance

Arrival date

We calculated the arrival date of the individuals as the day an individual was first observed in a year (May $1=$ day 1 ). To ensure the highest possible accuracy, we only considered arrival dates of individuals arriving in territories that were checked the preceding day without observation of a shrike ( $n=420$ males and 409 females). We used normal linear mixed models to analyse the arrival date for each sex separately. Year was considered a random factor while the explanatory variables were included as fixed factors. We used the temperature and the number of days with rainfall in May rather than in June and July to model arrival date. The other considered environmental factors were the same as those used for modelling survival and reproduction. As before, we calculated the proportion of temporal variance explained by the explanatory variables. All models for reproductive output and arrival date were fitted in $\mathrm{R}(\mathrm{R}$ Development Core Team 2004) using the function lmer.

\section{Results}

Apparent survival and change of reproductive success

Model selection revealed that apparent survival differed between adults with and without reproductive success the previous year and that there was evidence for an additive year effect (Table 1; Appendix 4 of Supplementary material). Whether or not apparent survival differed between the sexes remained uncertain. Resighting probabilities differed between sexes, but there was uncertainty about whether or not they varied also across time. The probabilities to change between classes of reproductive success depended on the preceding reproductive success, differed between sexes and varied in parallel across time (Table 1; Appendix 4 of Supplementary material).

The estimated apparent survival probabilities were slightly higher in males than in females, in both age and reproductive success classes (Fig. 2). Unsuccessful breeders in the preceding year had lower apparent survival probabilities. On average, juvenile survival was (mean \pm SE) $0.112 \pm 0.012$ and $0.078 \pm 0.015$ in males and females, respectively, adult survival of unsuccessful breeders was $0.317 \pm 0.023$ and $0.324 \pm 0.037$ in males and females, respectively, and adult survival of successful breeders was $0.583 \pm 0.030$ and $0.480 \pm 0.060$ in males and females, respectively. The estimated resighthing probabilities were very high for successful breeders $(0.999 \pm 0.001$, both sexes), but as expected lower for unsuccessful breeders (males: $0.433 \pm 0.042$, females: $0.150 \pm 0.021)$.

The estimated probabilities to reproduce successfully were higher in males than in females (Fig. 2). Breeders that reproduced successfully the year before had a higher probability to reproduce successfully in the current year 
Fig. 2 Annual estimates of apparent survival and of the probability to reproduce successfully in male and female red-backed shrikes as derived from the best time-dependent model (Table 1). Vertical lines 95\% confidence intervals
Males
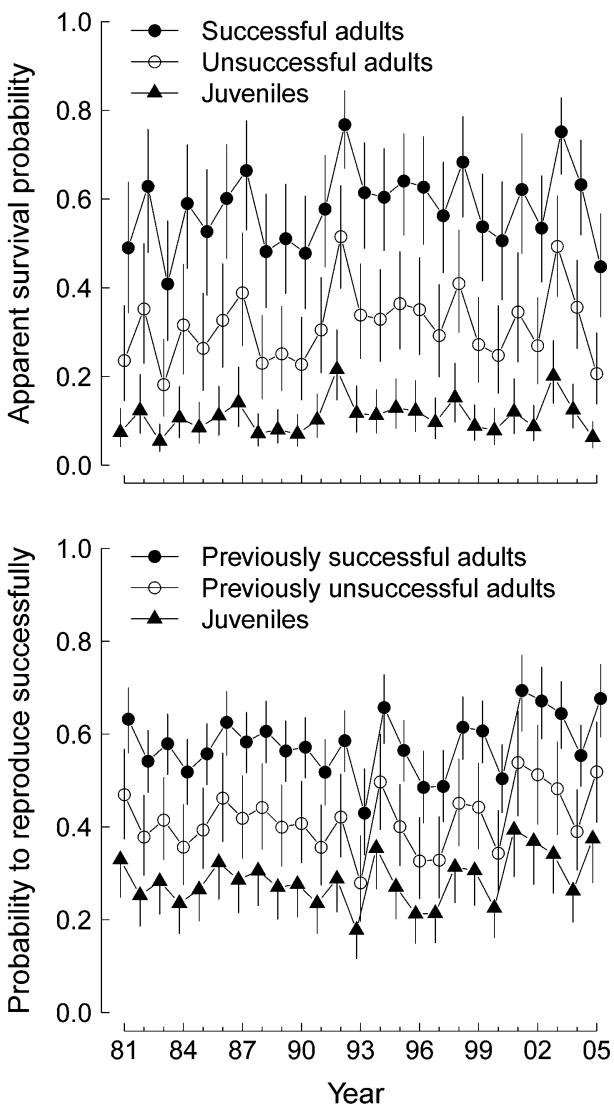

Females
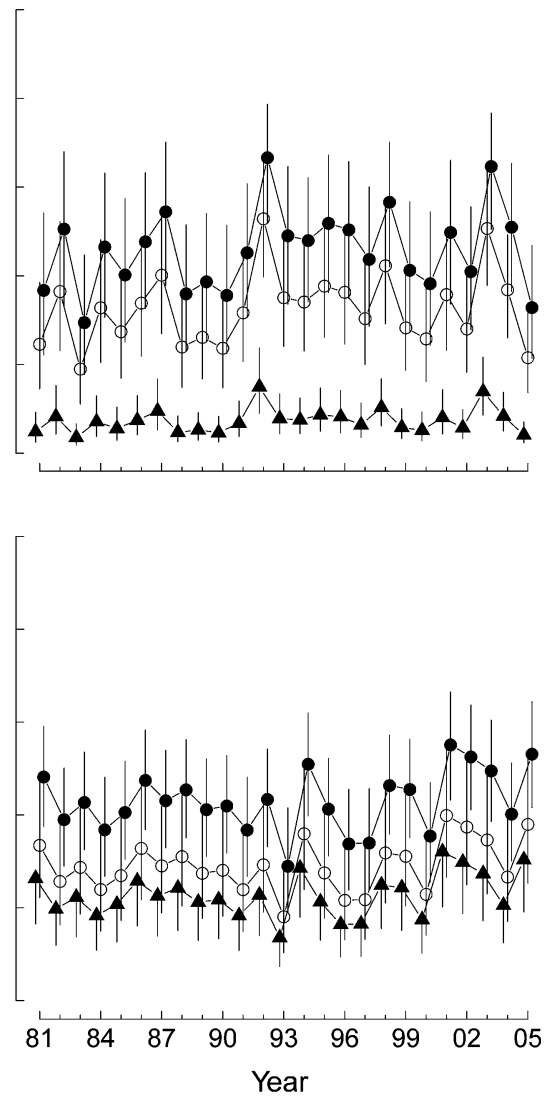

than failed breeders. The probability to reproduce successfully in shrikes breeding for the first time was lower than that of previously unsuccessful breeders (Fig. 2). On average, the probability to reproduce successfully in males was $($ mean \pm SE) $0.284 \pm 0.040,0.400 \pm 0.045$ and $0.568 \pm$ 0.034 for first time breeders, previously unsuccessful breeders and previously successful breeders, respectively. The corresponding figures for females were $0.237 \pm 0.053$, $0.301 \pm 0.059$ and $0.453 \pm 0.053$, respectively.

Each of the explanatory variables explained only a small proportion of the temporal deviance of apparent survival (maximum 0.131; Table 2). Temporal variance of apparent survival was positively related to temperature during breeding, Sahliean rainfall, S-African NDVI as well as population size, and negatively with to other environmental factors (Fig. 3; Table 2). However, the slopes were flat for most environmental factors. The strongest relationship and the largest proportion of the deviance explained were for temperature during breeding-shrike survival increased with temperature during the breeding period.

The probability to reproduce successfully was positively related to temperature during breeding as well as Sahelian NDVI and rainfall. Negative relationships were found in the other environmental factors and population size (Table 2; Fig. 4). The relationships were relatively steep with the Sahelian NDVI and the weather covariates during breeding, and these environmental factors explained $0.15-0.30$ of the temporal deviance.

Reproductive output

The Sahelian NDVI explained the largest proportion of the temporal variance of the reproductive output of successful breeding pairs (Table 3). The other environmental factors and population size explained much less of the temporal variance. Reproductive output increased with increasing Sahelian NDVI. Thus, the higher the primary production in the preceding migration period, the larger the reproductive output (Fig. 5). The same patterns were found in the reproductive output of both successful and unsuccessful breeders (Table 3).

\section{Arrival date}

Mean arrival date of males was 12 May and of females 14 May (Table 4). Temperature in May explained the largest proportion of the temporal variance of arrival date in males and females, while the other environmental factors were unimportant (Table 4). Shrikes arrived earlier in the breeding area when mean May temperatures were higher 
Table 2 Modelling apparent survival $(\phi)$ and change in class of reproductive success $(\psi)$ of red-backed shrikes in relation to environmental factors and population size

\begin{tabular}{|c|c|c|c|c|c|}
\hline Model & Deviance & $K$ & $R_{\mathrm{dev}}^{2}$ & Intercept & $\beta$ \\
\hline$\phi_{[\mathrm{J}, \mathrm{N}, \mathrm{S}]+\text { year }}$ & $5,333.37$ & 60 & - & - & - \\
\hline$\phi_{[J, N, S]+\text { Sahelian NDVI }}$ & $5,394.12$ & 37 & 0.004 & $0.333(0.118)$ & $-0.027(0.055)$ \\
\hline$\phi_{[J, N, S]+\text { Sahelian rainfall }}$ & $5,393.88$ & 37 & 0.008 & $0.327(0.117)$ & $0.034(0.049)$ \\
\hline$\phi_{[J, N, S]+S \text {-African } N D V I}$ & $5,391.58$ & 37 & 0.046 & $0.356(0.124)$ & $0.091(0.055)$ \\
\hline$\phi_{[J, N, S]+S \text {-African rainfall }}$ & $5,388.99$ & 37 & 0.088 & $0.309(0.115)$ & $0.130(0.056)$ \\
\hline$\phi_{[J, N, S]+E \text {-African } N D V I}$ & $5,392.63$ & 37 & 0.029 & $0.329(0.117)$ & $-0.073(0.055)$ \\
\hline$\phi_{[J, N, S]+\text { Temperature breeding }}$ & $5,386.36$ & 37 & 0.131 & $0.311(0.113)$ & $0.157(0.056)$ \\
\hline$\phi_{[J, N, S]+\text { Rainfall breeding }}$ & $5,389.61$ & 37 & 0.078 & $0.306(0.112)$ & $-0.114(0.052)$ \\
\hline$\phi_{[J, N, S]+\text { Population size }}$ & $5,390.44$ & 37 & 0.065 & $0.349(0.122)$ & $0.099(0.051)$ \\
\hline$\phi_{[J, N, S]}$ & $5,394.38$ & 36 & - & $0.326(0.117)$ & - \\
\hline$\psi_{\text {sex }+ \text { year }}^{J S, N S, S S}$ & $5,333.37$ & 60 & - & - & - \\
\hline$\psi_{\text {sex }+ \text { Sahelian NDVI }}^{J S, N S, S S}$ & $5,373.46$ & 37 & 0.309 & $0.371(0.132)$ & $0.288(0.069)$ \\
\hline$\psi_{\text {sex+Sahelian rainfall }}^{J S, N S, S S}$ & $5,391.19$ & 37 & 0.003 & $0.339(0.131)$ & $0.026(0.066)$ \\
\hline$\psi_{\text {sex }+S-A \text { African } N D V I}^{J S, N S, S S}$ & $5,386.41$ & 37 & 0.085 & $0.330(0.132)$ & $-0.145(0.065)$ \\
\hline$\psi_{\text {sex }+S \text {-African rainfall }}^{J S, N S, S S}$ & $5,387.70$ & 37 & 0.063 & $0.335(0.132)$ & $-0.137(0.072)$ \\
\hline$\psi_{\text {sex }+E-A f r i c a n}^{J S, N S, S S}$ NDVI & $5,389.32$ & 37 & 0.035 & $0.340(0.131)$ & $-0.101(0.071)$ \\
\hline$\psi_{\text {sex }+ \text { Temperature breeding }}^{J S, N S, S S}$ & $5,382.62$ & 37 & 0.151 & $0.362(0.131)$ & $0.215(0.074)$ \\
\hline$\psi_{\text {sex }+ \text { Rainfall breeding }}^{J S, N S, S S}$ & $5,383.79$ & 37 & 0.130 & $0.376(0.131)$ & $-0.192(0.071)$ \\
\hline$\psi_{\text {sex }+ \text { Population size }}^{J S, N S S S}$ & $5,390.19$ & 37 & 0.020 & $0.361(0.132)$ & $-0.075(0.070)$ \\
\hline$\psi_{\mathrm{sex}}^{\mathrm{JS}, \mathrm{NS}, \mathrm{SS}}$ & $5,391.35$ & 36 & - & $0.339(0.131)$ & - \\
\hline
\end{tabular}

The basic model structure is $\phi_{[\mathrm{J}, \mathrm{N}, \mathrm{S}]+\text { year }}, \psi_{\mathrm{sex}+\text { year }}^{\mathrm{JS}, \mathrm{NS}, p_{[\mathrm{N}, \mathrm{S}]+\text { sex }}}$ (best model in Table 1 ). However, in the table, only the parameter type that was exchanged is denoted. Given are the model deviance, the number of estimated parameters $(K)$, the proportion of deviance explained by the explanatory variable $\left(R_{\mathrm{dev}}^{2}\right)$, and the estimated intercept (refers to successful breeders for $\phi$ and to previously successfully breeding males for $\psi$ ) and the slope ( $\beta$; SE in parentheses). The slope $(\beta)$ expresses the change in terms of 1 SD of the corresponding explanatory variable. Sahelian NDVI NDVI of the Sahelian stopover area in autumn, Sahelian rainfall Amount of rainfall in the Sahelian stopover area in autumn, $S$-African NDVI NDVI in the wintering area in southern Africa in November-March, E-African NDVI NDVI in the stopover area in eastern Africa in April, Temperature breeding temperature in the breeding area in June and July, Rainfall breeding number of days with rainfall in the breeding area in June and July, Population size population size in the breeding area

(Fig. 6), and the relationship was slightly more pronounced in males than in females.

\section{Discussion}

Survival, reproduction and arrival of red-backed shrikes at the breeding sites were highly variable across the 25 study years. With a few exceptions, little of this temporal variation could be attributed to environmental factors at different stages in the annual cycle and to the size of the breeding population. However, the probability to reproduce successfully and the number of fledglings of successful broods were both positively correlated with the NDVI in the Sahel. This is evidence for a carry-over effect, possibly triggered by the variation in food supply in the Sahel, where red-backed shrikes spend the autumn. Survival and reproductive success depended on weather during the reproductive period. Arrival date was correlated with the temperature when arriving on the breeding grounds. Demographic rates were thus affected by environmental factors operating during both breeding and non-breeding, suggesting that the dynamics of the local population depended on local and non-local conditions.

Structural and temporal variation in demographic rates

Since our estimate of apparent survival is the product of true survival and philopatry (Burnham 1993), the observed temporal variation might also be due to variation in 

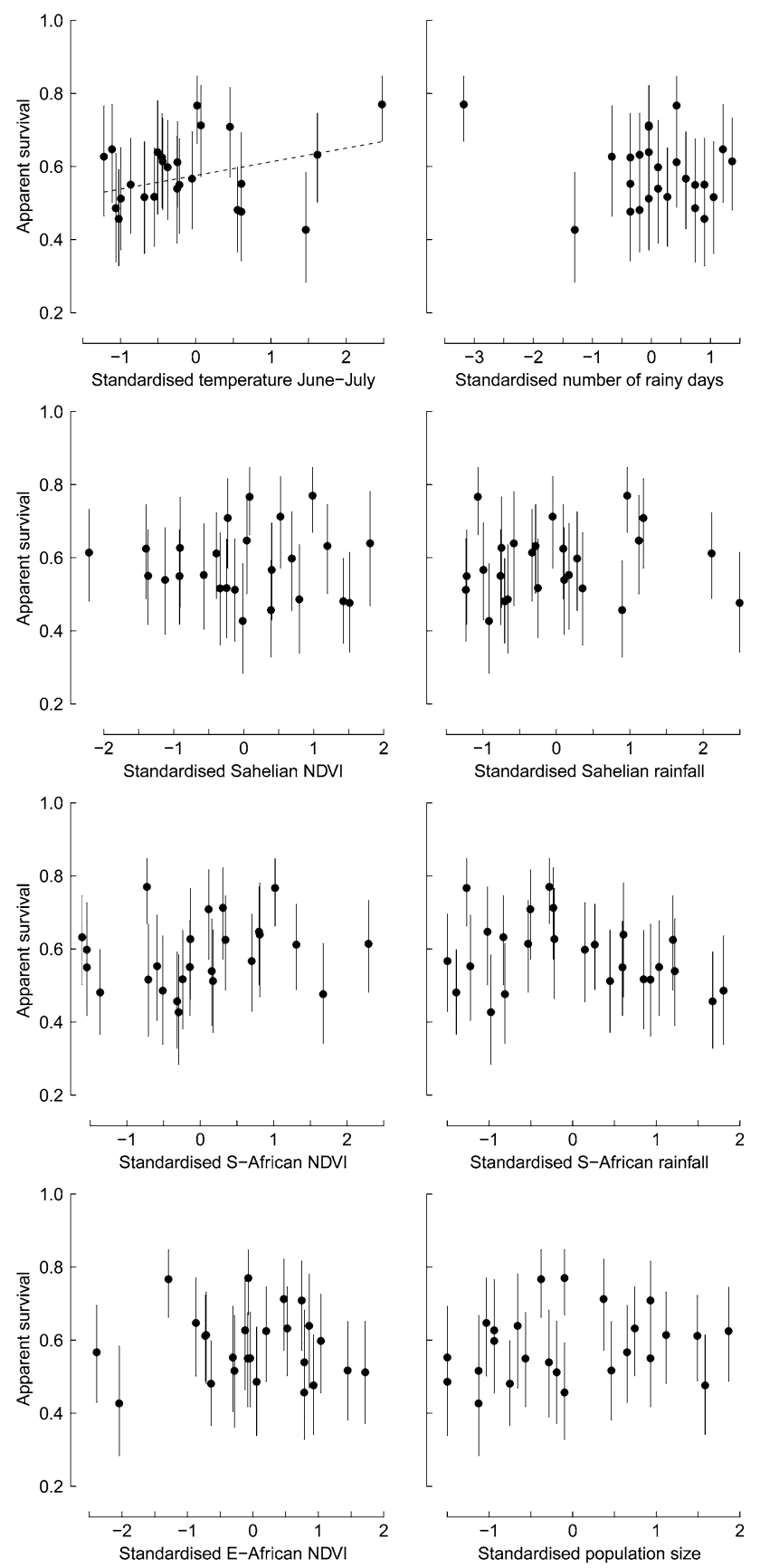

Fig. 3 Annual probabilities of apparent survival by previously successfully breeding red-backed shrike males, as estimated from the best time-dependent model (Table 1) in relation to the standardised environmental factors and population size. Vertical lines 95\% confidence intervals. The structure of regression lines (estimated from the models in Table 2) shows how much of the deviance is explained by the corresponding explanatory variable (no line $0-0.1$, broken line $0.1-0.2$, solid line $>0.2$ ). The graphs for the other age- and sex-classes are not shown; since the best models have an additive temporal structure, they have the same pattern

emigration from the study area. If this had been true, we would have expected that survival of successful breeders shows no or only little temporal variation, because these
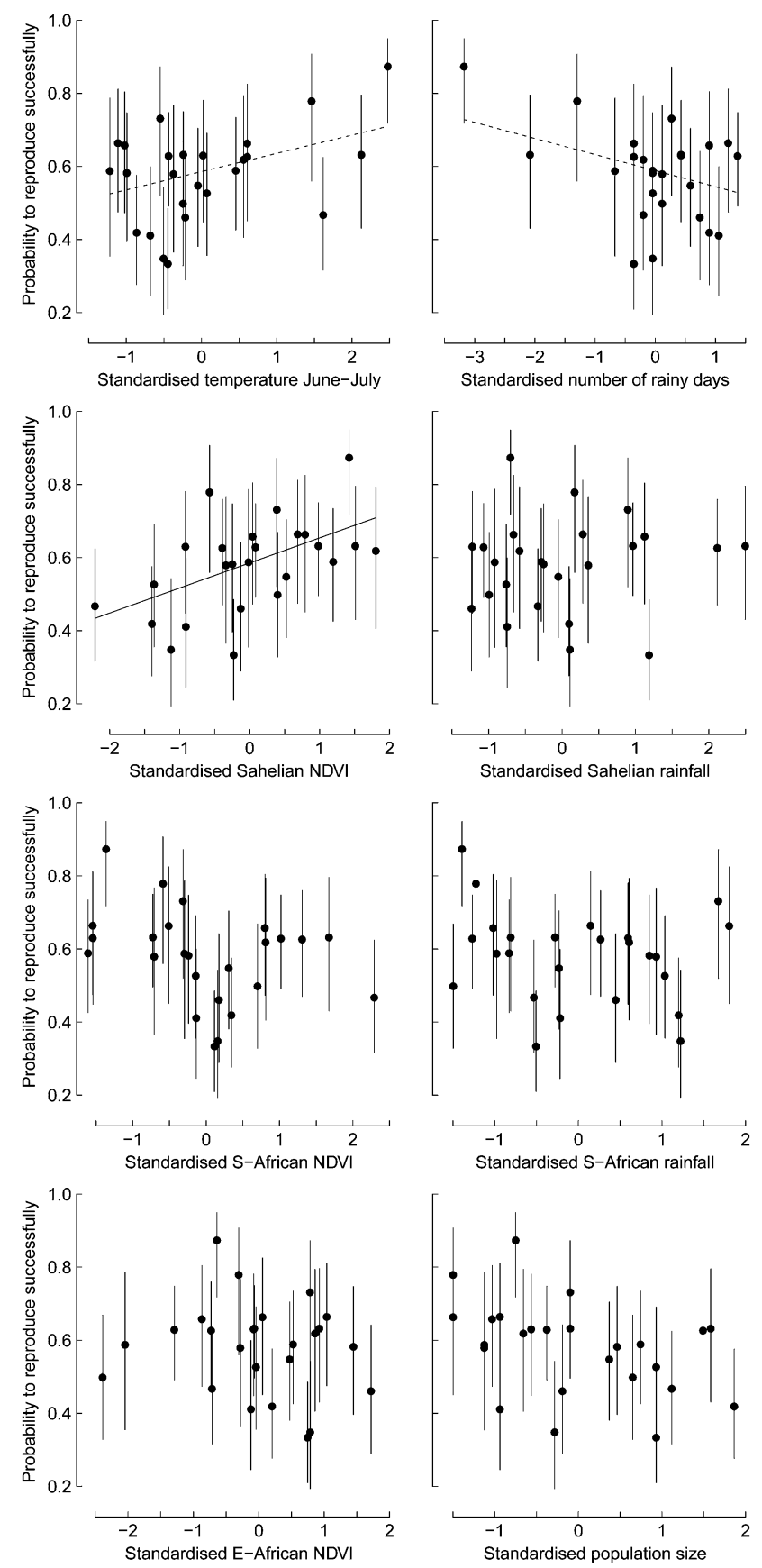

Fig. 4 Annual probabilities of reproducing successfully by previously successfully breeding red-backed shrike males, as estimated from the best time-dependent model (Table 1) in relation to the standardised environmental factors and population size. Vertical lines $95 \%$ confidence intervals. The structure of regression lines (estimated from the models in Table 2) shows how much of the deviance is explained by the corresponding explanatory variable (no line $0-0.1$, broken line $0.1-0.2$, solid line $>0.2$ ). The graphs for the other ageand sex-classes are not shown; since the best models have an additive temporal structure they have the same pattern

individuals are mostly philopatric (Jakober and Stauber 1989). Because temporal variation of successful breeders was similar to that of other individuals, we are confident 

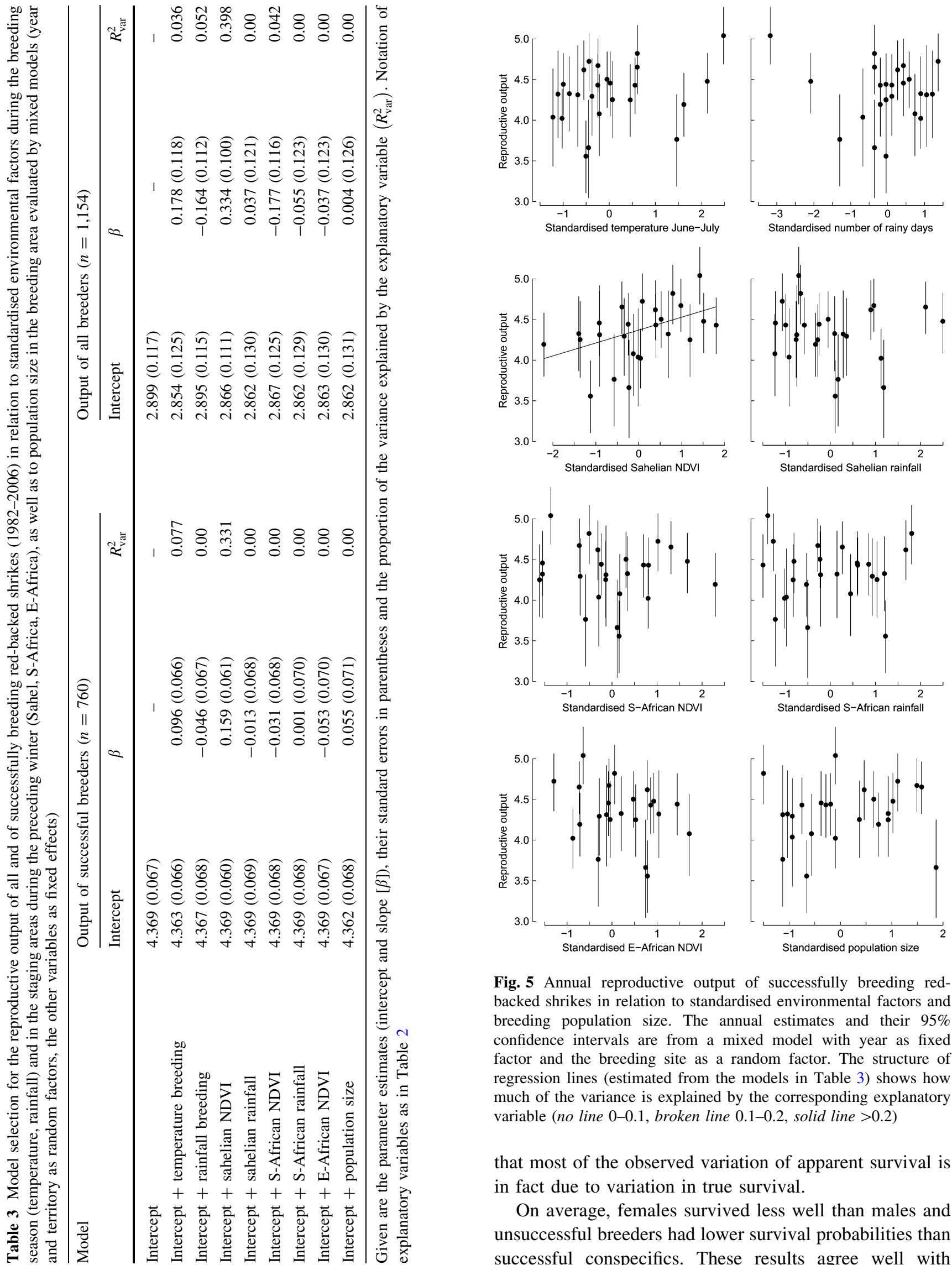

Fig. 5 Annual reproductive output of successfully breeding redbacked shrikes in relation to standardised environmental factors and breeding population size. The annual estimates and their 95\% confidence intervals are from a mixed model with year as fixed factor and the breeding site as a random factor. The structure of regression lines (estimated from the models in Table 3) shows how much of the variance is explained by the corresponding explanatory variable (no line $0-0.1$, broken line $0.1-0.2$, solid line $>0.2$ )

that most of the observed variation of apparent survival is in fact due to variation in true survival.

On average, females survived less well than males and unsuccessful breeders had lower survival probabilities than successful conspecifics. These results agree well with 
Table 4 Modelling of arrival dates of red-backed shrike males and females (1982-2006) in relation to environmental factors and population size based on a mixed model with year as random factor

\begin{tabular}{|c|c|c|c|c|c|c|}
\hline \multirow[t]{2}{*}{ Model } & \multicolumn{3}{|c|}{ Males $(n=420)$} & \multicolumn{3}{|c|}{ Females $(n=409)$} \\
\hline & Intercept & $\beta$ & $R_{\mathrm{var}}^{2}$ & Intercept & $\beta$ & $R_{\mathrm{var}}^{2}$ \\
\hline Intercept & $12.10(0.73)$ & - & - & $13.93(0.68)$ & - & - \\
\hline Intercept + temperature may & $12.15(0.66)$ & $-1.97(0.69)$ & 0.251 & $13.97(0.64)$ & $-1.62(0.68)$ & 0.189 \\
\hline Intercept + rainfall may & $12.11(0.73)$ & $0.65(0.75)$ & 0.00 & $13.95(0.68)$ & $0.75(0.69)$ & 0.011 \\
\hline Intercept + sahelian NDVI & $12.10(0.74)$ & $0.32(0.75)$ & 0.00 & $13.94(0.69)$ & $0.56(0.68)$ & 0.00 \\
\hline Intercept + sahelian rainfall & $12.11(0.71)$ & $1.14(0.72)$ & 0.064 & $13.95(0.69)$ & $-0.62(0.70)$ & 0.00 \\
\hline Intercept + S-African NDVI & $12.10(0.75)$ & $0.20(0.76)$ & 0.00 & $13.92(0.70)$ & $0.24(0.70)$ & 0.00 \\
\hline Intercept + S-African rainfall & $12.11(0.74)$ & $-0.52(0.75)$ & 0.00 & $13.93(0.68)$ & $-0.57(0.70)$ & 0.00 \\
\hline Intercept + E-African NDVI & $12.10(0.75)$ & $-0.09(0.77)$ & 0.00 & $13.94(0.69)$ & $-0.39(0.72)$ & 0.00 \\
\hline Intercept + population size & $12.11(0.73)$ & $-0.67(0.75)$ & 0.00 & $2.862(0.131)$ & $0.004(0.126)$ & 0.00 \\
\hline
\end{tabular}

Given are the parameter estimates (intercept and slope $[\beta]$ ), their standard errors in parentheses and the proportion of the variance explained by the explanatory variable $\left(R_{\text {var }}^{2}\right)$. The intercept refers to the mean arrival date (1 May = day 1$)$. Model notation as in Table 3, plus Temperature May mean temperature in the breeding area in May, Rainfall May number of days with rainfall in the breeding area in May

findings in barn swallows Hirundo rustica (Schaub and von Hirschheydt 2009) and are likely caused by differential emigration probabilities from the study area. In birds, females generally have higher dispersal probabilities (Greenwood and Harvey 1982) and unsuccessful breeders more frequently disperse than successful breeders (Pasinelli et al. 2007). Survival probabilities of both sexes, age classes and classes of reproductive success varied in parallel across time suggesting that a common large-scale factor was operating to which all individuals were similarly sensitive.

The probability to reproduce successfully was depending on the reproductive success in the preceding year, indicating individual differences of reproductive performance, e.g. due to differences in quality of individuals or territory. The temporal variation of successful reproduction was the same in previously unsuccessful and previously successful breeders, as well as in birds breeding for the first time. Again, this suggests that there was a common factor affecting reproduction to which all birds in a similar fashion. However, the temporal pattern of apparent survival and to reproduce successfully differed (Fig. 2), indicating that the main factors impacting these demographic rates differed.

Effects of explanatory variables on temporal variation of demographic rates

Most of the explanatory variables accounted for relatively little of the observed temporal variation of the demographic rates. This is true in particular for the environmental factors at the wintering (S-African) and spring (E-African) stopover areas, as well as for breeding population size. We assume NDVI and rainfall to be positively correlated with food supply, suggesting that variations in food supply in these areas were unlikely to be the main mechanism driving variation in survival, reproduction and timing of arrival. However, it is possible that the environmental factors considered were less well correlated with food supply than expected or that the spatio-temporal pattern of red-backed shrike migration differed from our assumptions. These short-comings can only be solved by field studies in the stopover and wintering areas to assess variation in food supply and by detailed studies on the spatio-temporal pattern of shrike migration, e.g. by using geolocators (Bächler et al. 2010).

Variation of demographic rates was also unrelated to breeding population size, suggesting independence of density. Since there is evidence that the population growth rate is negatively affected by population density, but without knowing the mechanism (Pasinelli et al. 2011), it is likely that other demographic rates not considered here, such as dispersal, are affected by density. In addition, we had no data on the population density at the stopover or wintering sites. Thus, we were unable to test whether variation of demographic rates was associated with density at these areas. It may well be that density dependence is operating at these places and thus induces temporal variation in demographic rates.

The environmental factors that explained some of the temporal variation in demographic rates were the NDVI in the Sahel as well as temperature and the number of rainy days in the breeding period. The probability to reproduce successfully and the reproductive output increased with increasing NDVI in the autumn stopover area. This indicates that the reproductive performance increases with food supply encountered at a stopover area visited during the preceding autumn migration. This kind of carry-over effect 

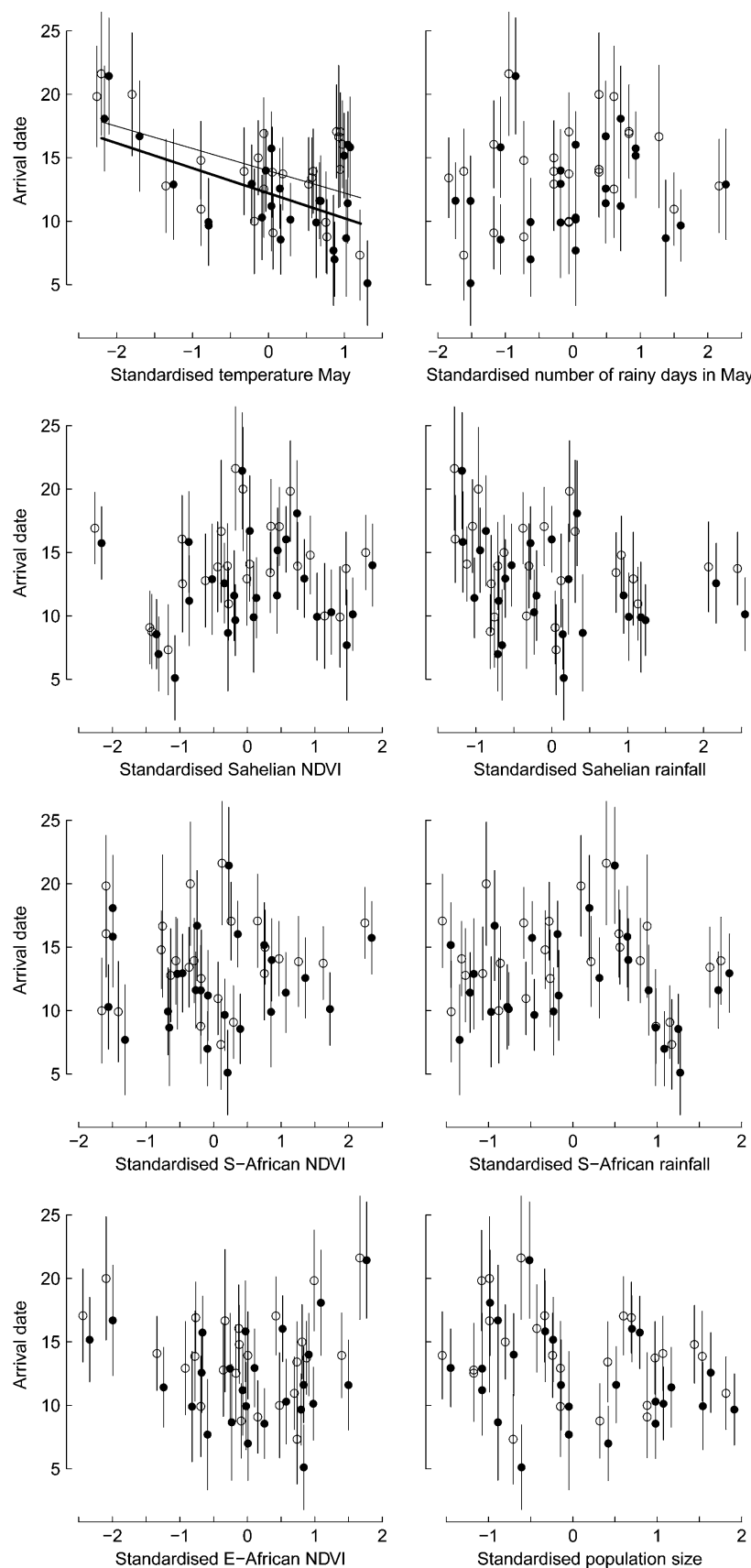

Fig. 6 Mean annual arrival date (1 May = day 1) of red-backed shrike males (dots) and females (circles) in relation to standardised environmental factors and breeding population size. The annual estimates and their $95 \%$ confidence intervals are from a fixed effects model with year. The structure of regression lines (estimated from the models in Table 4) shows how much of the variance is explained by the corresponding explanatory variable (no line $0-0.1$, broken line $0.1-0.2$, solid line $>0.2$; thick males, thin females)

is unexpected and remarkable, because it implies that events three-quarters of a year apart are linked. Carry-over effects on reproduction or arrival found so far are explained by a reduced body condition upon arrival (body reserves or sexual development) of individuals which experienced food shortage during non-breeding or spring stopover (Norris et al. 2004; Saino et al. 2004b; Studds and Marra 2005; Bauchinger et al. 2008). Although it is likely that the carry-over effect in the red-backed shrikes is also a consequence of their body condition, the functional mechanism of this process remains speculative. A possibility is that the premigratory fattening in the Sahelien stopover area is hampered when food availability is low, and that the birds are unable to recover. Successful recovery may be difficult as moult taking place at the same time is an energetically demanding activity (Klaassen 1995; Bruderer 2007). The mechanism resulting in low reproductive success is not just a consequence of later arrival, since this was not related to NDVI in the African stopover areas. This suggests that shrikes did not delay their departure from the wintering areas nor that they migrate more slowly when environmental conditions in the autumn staging area were poor. To understand the mechanisms underlying this carryover effect, it would be necessary to study body condition at all the three areas where shrikes spend much of their time.

Several studies have shown that the reproductive success of red-backed shrikes depends on the weather conditions during breeding (Jakober and Stauber 2004; Husek and Adamik 2008). This is consistent with our results and we showed that annual survival is also affected. Therefore, if good weather prevails and thus insect food supply is high (Schaub 1996), shrikes arrived earlier on the breeding area, had higher reproductive output and possibly survived better. However, these relationships, in particular for survival, are partially due to the extremely warm and dry year of 2003 (Fig. 2). If this year is excluded from the linear relationships with the weather factors, the estimated slopes are closer to zero.

The lack of sensitivity of survival to variation in NDVI and rainfall in Africa contrasts with other long-distance migrants, for which variation of these environmental factors was often an important determinant of variation in survival (Kanyamibwa et al. 1990; Peach et al. 1990, 1995; Szep 1995; Cowley and Siriwardena 2005; Robinson et al. 2008). As the Sahel is frequently subject to severe droughts causing food shortage (Nicholson 2001), it is not surprising that survival is affected in species that spend their complete non-breeding season in this area. In contrast to these species, red-backed shrikes spend only a relatively short time in the Sahel; briefly after the regular rainfalls. This may explain why droughts have no effect on shrike survival. Still, survival of eastern white storks Ciconia ciconia, which have a similar spatio-temporal migration pattern as red-backed shrikes, is negatively correlated with vegetation development in the Sahel (Schaub et al. 2005). Storks require larger food items than red-backed shrikes, and perhaps the development of large insects depends more 
strongly on the vegetation and rainfall than that of small insects. In the South African wintering areas, shrikes can aggregate when local food is building up after local rainfall and, although they show some site fidelity (Herremans and Herremans-Tonnoeyr 1995), they move within the vast potential wintering range in southern Africa (Bruderer and Bruderer 1994).

Understanding population dynamics of red-backed shrikes

Population dynamics of red-backed shrikes are characterized by relatively strong fluctuations, caused by stochastic and deterministic factors (Pasinelli et al. 2011). As expected, we found survival and reproduction to be highly variable across time. Part of this temporal variation could be explained by environmental factors in the breeding areas and in the Sahelian stopover area, suggesting that the dynamics of the local population is driven by local and non-local factors. However, most of the temporal variation of demographic rates and thus of population dynamics remained unexplained. We suspect that events during the migratory flights (during the less stable phases) and competition at the non-breeding staging areas to be responsible for temporal variation, in particular in survival probabilities (Sillett and Holmes 2002).

Although we had excellent demographic and reasonable environmental data to study population dynamics of a migratory bird species, the large temporal variation in demographic rates remained largely unexplained and its link to population dynamics is elusive. To close this gap of knowledge, the complete demography, e.g. through integrated models (Schaub et al. 2007), needs to be considered and more accurate information on density and food supply at stopover and wintering areas should be included. Hitherto, such information is hardly available. The study of the population dynamics of migrants remains a challenge, and integrated life-cycle studies following a species along its annual cycle should be studied with priority.

Acknowledgments We thank Renate Zeeb for her assistance during the intensive field work, G. Häfliger for his support to extract the NDVI data, and L. Schifferli, B. Bruderer, G. Pasinelli, M. Kéry, S. Hahn, P. Marra, S. Bearhop as well as several reviewers for helpful comments on the manuscript.

\section{References}

Bächler E, Hahn S, Schaub M, Arlettaz R, Jenni L, Fox JW, Afanasyev V, Liechti F (2010) Year-round tracking of small trans-Saharan migrants using light-level geolocators. Plos ONE 5:e9566
Baker AJ, Gonzalez PM, Piersma T, Niles LJ, De Lima De Serrano Do Nascimento, Atkinson PW, Clark NA, Minton CDT, Peck MK, Aarts G (2004) Rapid population decline in red knots: fitness consequences of decreased refuelling rates and late arrival in Delaware Bay. Proc R Soc Lond B 271:875-882

Bauchinger U, Van't Hof T, Biebach H (2008) Migratory stopover conditions affect the developmental state of male gonads in garden warblers (Sylvia borin). Horm Behav 54:312-318

Bearhop S, Hilton GM, Votier SC, Waldron S (2004) Stable isotope ratios indicate that body condition in migrating passerines is influenced by winter habitat. Proc R Soc Lond B 271:215-218

Berthold P, van den Bossche W, Fiedler W, Kaatz C, Kaatz M, Leshem Y, Nowak E, Querner U (2001) Detection of a new important staging and wintering area of the White Stork Ciconia ciconia by satellite tracking. Ibis 143:450-455

Bruderer B (2007) Notes on the moult of red-backed shrikes (Lanius collurio) in their nonbreeding range. J Ornithol 148:557-561

Bruderer B, Bruderer H (1993) Distribution and habitat preference of Red-backed Shrike (Lanius collurio) in southern Africa. Ostrich 64:141-147

Bruderer B, Bruderer H (1994) Numbers of Red-backed Shrikes (Lanius collurio) in different Habitats of South Africa. Bulletin B O C 114:192-202

Bruderer B, Bruderer H (2008) Der Neuntöter Lanius collurio im Winterquartier. Ornithol Beob 105:231-266

Burnham KP (1993) A theory for combined analysis of ring recovery and recapture data. In: Lebreton JD (ed) Marked individuals in the study of bird populations. Birkhäuser, Basel, pp 199-213

Burnham KP, Anderson DR (2002) Model selection and multimodel inference: a practical information theoretic approach. Springer, New York

Choquet R, Lebreton JD, Gimenez O, Reboulet AM, Pradel R (2009a) U-CARE: utilities for performing goodness of fit tests and manipulating CApture-REcapture data. Ecography 32:10711074

Choquet R, Rouan L, Pradel R (2009b) Program E-SURGE: a software application for fitting multievent models. In: Thomson DL, Cooch EG, Conroy MJ (eds) Modeling demographic processes in marked populations. Springer, New York, pp 845-865

Cowley E, Siriwardena GM (2005) Long-term variation in survival rates of Sand Martins Riparia riparia: dependence on breeding and wintering ground weather, age and sex, and their population consequences. Bird Study 52:237-251

Freckleton RP, Watkinson AR, Green RE, Sutherland BJ (2006) Census error and the detection of density dependence. J Anim Ecol 75:837-851

Geiser S, Arlettaz R, Schaub M (2008) Impact of weather variation on feeding behaviour, nestling growth and brood survival in wrynecks Jynx torquilla. J Ornithol 149:597-606

Glutz von Blotzheim UN, Bauer KM (1993) Lanius collurio Linnaeus 1758-Rotrückenwürger, Neuntöter. In: Glutz von Blotzheim UN, Bauer KM (eds) Handbuch der Vögel Mitteleuropas, vol 13/II (Passeriformes, 4. Teil). Aula, Wiesbaden, pp 1140-1220

Gordo O, Sanz JJ (2008) The relative importance of conditions in wintering and passage areas on spring arrival dates: the case of long-distance Iberian migrants. J Ornithol 149:199-210

Greenwood PJ, Harvey PH (1982) The natal and breeding dispersal of birds. Annu Rev Ecol Syst 13:1-21

Grosbois V, Gimenez O, Gaillard JM, Pradel R, Barbraud C, Clobert J, Möller AP, Weimerskirch H (2008) Assessing the impact of climate variation on survival in vertebrate populations. Biol Rev 83:357-399

Haas CA (1998) Effects of prior nesting success on site fidelity and breeding dispersal: an experimental approach. Auk 115:929-936

Harris T (2000) Shrikes and bush-shrikes. Helm, London 
Harrison JA, Allan DG, Underhill LG, Herremans M, Tree AJ, Parker V, Brown CJ (eds) (1997) The atlas of southern African birds, vol 2: passerines. BirdLife South Africa, Johannesburg

Harrison XA, Blount JD, Inger R, Norris DR, Bearhop S (2011) Carry-over effects as drivers of fitness differences in animals. J Anim Ecol 80:4-18

Herremans M, Herremans-Tonnoeyr D (1995) Non-breeding sitefidelity of Red-backed Shrikes (Lanius collurio) in Botswana. Ostrich 66:145-147

Hubalek Z (2003) Spring migration of birds in relation to North Atlantic Oscillation. Folia Zool 52:287-298

Husek J, Adamik P (2008) Long-term trends in the timing of breeding and brood size in the red-backed shrike Lanius collurio in the Czech Republic, 1964-2004. J Ornithol 149:97-103

Jakober H, Stauber W (1987) Habitatansprüche des Neuntöters (Lanius collurio) und Massnahmen für seinen Schutz. Beih Veröff Nat Land Baden-Württem 48:25-53

Jakober H, Stauber W (1989) Beeinflussen Bruterfolg und Alter die Ortstreue des Neuntöters (Lanius collurio)? Vogelwarte 35:32-36

Jakober H, Stauber W (2004) Ergebnisse einer langjährigen Populationsuntersuchung am Neuntöter (Lanius collurio). Mitt Ver Sächs Ornithol 9:307-315

Jakober H, Stauber W, Bairlein F, Voss M (2007) Analysis of stable isotopes in feathers of red-backed shrikes (Lanius collurio): no evidence for different wintering habitats of males and females. J Ornithol 148:129-131

Kanyamibwa S, Schierer A, Pradel R, Lebreton JD (1990) Changes in adult annual survival rates in a western European population of the white stork (Ciconia ciconia). Ibis 132:27-35

Klaassen M (1995) Moult and basal metabolic costs in males of two subspecies of stonechats: the European Saxicola torquata rubicula and the East African $S$. $t$. axillaris. Oecologia 104:424-432

Lebreton JD, Nichols JD, Barker RJ, Pradel R, Spendelow JA (2009) Modeling individual animal histories with multistate capturerecapture models. Adv Ecol Res 41:87-173

Lefranc N (1993) Les pies-grièches d'Europe, d'afrique du Nord et du Moyen-Orient. Delachaux et Niestlé, Lausanne

Marra PP, Hobson KA, Holmes RT (1998) Linking winter and summer events in a migratory bird by using stable-carbon isotopes. Science 282:1884-1886

Moore FR, Yong W (1991) Evidence of food-based competition among passerine migrants during stopover. Behav Ecol Sociobiol 28:85-90

Müller M, Pasinelli G, Schiegg K, Spaar R, Jenni L (2005) Ecological and social effects on reproduction and local recruitment in the red-backed shrike. Oecologia 143:37-50

Newton I (2008) The migration ecology of birds. Academic, London

Nichols JD, Kendall WL, Hines JE, Spendelow JA (2004) Estimation of sex-specific survival from capture-recapture data when sex is not always known. Ecology 85:3192-3201

Nicholson SE (2001) Climatic and environmental change in Africa during the last two centuries. Clim Res 17:123-144

Nicholson SE, Davenport ML, Malo AR (1990) A comparison of the vegetation response to rainfall in the Sahel and East Africa, using normalized difference vegetation index from NOAA AVHRR. Clim Change 17:209-241

Norris DR, Marra PP, Kyser TK, Sherry TW, Ratcliffe LM (2004) Tropical winter habitat limits reproductive success on the temperate breeding grounds in a migratory bird. Proc R Soc Lond B 271:59-64

Pasinelli G, Müller M, Schaub M, Jenni L (2007) Possible causes and consequences of philopatry and breeding dispersal in red-backed shrikes Lanius collurio. Behav Ecol Sociobiol 61:1061-1074
Pasinelli G, Schaub M, Häfliger G, Frey M, Jakober H, Müller M, Stauber W, Tryjanowski P, Zollinger J-L, Jenni L (2011) Impact of density and environmental factors on population fluctuations in a migratory passerine. J Anim Ecol 80:225-234

Peach W, Baillie SR, Underhill L (1990) Survival of British Sedge Warblers (Acrocephalus schoenobaenus) in relation to west African rainfall. Ibis 133:300-305

Peach WJ, Crick HQP, Marchant JH (1995) The demography of the decline in the British willow warbler population. J Appl Stat 22:905-922

Pearson DJ (1990) Palaearctic passerine migrants in Kenya and Uganda: temporal and spatial patterns of their movements. In: Gwinner E (ed) Bird migration. Physiology and ecophysiology. Springer, Berlin, pp 44-59

Pearson DJ, Backhurst GC (1976) The southward migration of Palaearctic birds over Ngulia, Kenya. Ibis 118:78-105

Pettorelli N, Vik JO, Mysterud A, Gaillard JM, Tucker CJ, Stenseth NC (2005) Using the satellite-derived NDVI to assess ecological responses to environmental change. Trends Ecol Evol 20:503-510

Pradel R, Wintrebert CMA, Gimenez O (2003) A proposal for a goodness-of-fit test to the Arnason-Schwarz multistate capturerecapture model. Biometrics 59:43-53

R Development Core Team (2004) R: a language and environment for statistical computing. R Foundation for Statistical Computing, Vienna

Ratikainen II, Gill JA, Gunnarsson TG, Sutherland WJ, Kokko H (2008) When density dependence is not instantaneous: theoretical developments and management implications. Ecol Lett 11:184-198

Robinson RA, Balmer DE, Marchant JH (2008) Survival rates of hirundines in relation to British and African rainfall. Ringing Migr 24:1-6

Rodenhouse NL, Sillett TS, Doran PJ, Holmes RT (2003) Multiple density-dependence mechanisms regulate a migratory bird population during the breeding season. Proc R Soc Lond B 270:2105-2110

Roos S, Pärt T (2004) Nest predators affect spatial dynamics of breeding red-backed shrikes (Lanius collurio). J Anim Ecol 73:117-127

Runge MC, Marra PP (2005) Modeling seasonal interactions in the population dynamics of migratory birds. In: Greenberg R, Marra PP (eds) Birds of two worlds: the ecology and evolution of migration. The John Hopkins University Press, Baltimore, pp 375-389

Saino N, Szép T, Ambrosini R, Romano M, Möller AP (2004a) Ecological conditions during winter affect sexual selection and breeding in a migratory bird. Proc R Soc Lond B 271:681-686

Saino N, Szép T, Romano M, Rubolini D, Spina F, Möller AP (2004b) Ecological conditions during winter predict arrival date at the breeding quarters in a trans-Saharan migratory bird. Ecol Lett 7:21-25

Schaub M (1996) Jagdverhalten und Zeitbudget von Rotkopfwürgern (Lanius senator) in der Nordwestschweiz. J Ornithol 137:213227

Schaub M, von Hirschheydt H (2009) Effect of current reproduction on apparent survival, breeding dispersal, and future reproduction in barn swallows assessed by multistate capture-recapture models. J Anim Ecol 78:625-635

Schaub M, Kania W, Köppen U (2005) Variation of primary production during winter induces synchrony in survival rates in migratory white storks Ciconia ciconia. J Anim Ecol 74:656666

Schaub M, Gimenez O, Sierro A, Arlettaz R (2007) Use of integrated modeling to enhance estimates of population dynamics obtained from limited data. Conserv Biol 21:945-955 
Sillett TS, Holmes RT (2002) Variation in survivorship of a migratory songbird throughout its annual cycle. J Anim Ecol 71:296-308

Simek J (2001) Patterns of breeding fidelity in the red-backed shrike (Lanius collurio). Ornis Fenn 78:61-71

Studds CE, Marra PP (2005) Nonbreeding habitat occupancy and population processes: an upgrade experiment with a migratory bird. Ecology 86:2380-2385

Szep T (1995) Survival rates of Hungarian sand martins and their relationship with Sahel rainfall. J Appl Stat 22:891-904

Thomson DL, Douglas-Home H, Furness RW, Monaghan P (1996) Breeding success and survival in the common swift Apus apus: a long-term study on the effects of weather. J Zool 239:29-38
Todd MC, Washington R, Cheke RA, Kniveton D (2002) Brown locust outbreaks and climate variability in southern Africa. J Appl Ecol 39:31-42

Tryjanowski P, Kuzniak S, Sparks T (2002) Earlier arrival of some farmland migrants in western Poland. Ibis 144:62-68

Veistola S, Lehikoinen E, Eeva T (1997) Weather and breeding success at high latitudes - the pied flycatcher Ficedula hypoleuca and the Siberian tit Parus cinctus. Ornis Fennica 74:89-98

Webster MS, Marra PP, Haig SM, Bensch S, Holmes RT (2002) Links between worlds: unraveling migratory connectivity. Trends Ecol Evol 17:76-83 